\title{
Reaching Agreements through Fuzzy Counter-Offers
}

\author{
Javier Carbo $^{1}$, Jose M. Molina ${ }^{1}$, and Jorge Dávila ${ }^{2}$ \\ ${ }^{1}$ Computer Science Department, Univ. Carlos III, \\ 28911 Leganes, Madrid, Spain \\ jcarbo@inf.uc3m.es, molina@ia.uc3m.es \\ ${ }^{2}$ Computer Science Faculty, Univ. Politécnica de Madrid, \\ 28660 Boadilla, Madrid, Spain \\ jdavila@fi.upm.es
}

\begin{abstract}
Automated negotiations require a more elaborated dialogue where agents would explain offer rejections in a general and vague way. We propose to represent the disappointment about an offer through fuzzy logic. Specifically we study two alternatives: a piece-wise fuzzy set or a linguistic label applied to each attribute of the offer. These alternatives are evaluated comparing the performance of both types of counter-offers with a classical approach based on linear programming. Therefore, the media of negotiation length, benefits and percentage of agreements allow us to conclude the accuracy of the alternatives proposed.
\end{abstract}

\section{Introduction}

Several types of automated negotiations have been proposed. Among them, agentmediated auctions have become relatively popular [1]. Nevertheless auctions are very different from the daily bargain of markets. Most people is not familiar with their rules. If agents intended to reflect the real behavior of human society, then a humanlike negotiation would be searched. The most human-like negotiation scheme proposed involves the use of arguments in order to persuade the other part of improving the offer [2].

We propose the use of fuzzy sets to express the counter-offer of buyers in a negotiation. Each attribute of the agreement to negotiate has associated a fuzzy set to persuade the merchant to improve the offer. Both linguistic and numerically defined fuzzy sets were applied to compare with corresponding negotiations where buyers reject the offer of merchants in a concrete way.

\section{Fuzzy Counter-Offers in Automated Negotiations}

The negotiation setup proposed defines the preferences function of each part as a boundary value and a weight for each negotiation attribute. Therefore an agreement is reached when the offer satisfies the next requirements: 
$\forall \mathrm{i} \in$ Attributes, and weight $[\mathrm{i}]>0$ : offer[i] $>$ threshold[i] ,

$\forall \mathrm{j} \in$ Attributes, and weight $[\mathrm{j}]<0$ : offer $[\mathrm{j}]<$ threshold $[\mathrm{j}]$,

$\forall \mathrm{k} \in$ Attributes: benefit $>\sum_{\mathrm{k}}$ weight[k] $\cdot$ offer[k] .

The weights and thresholds of each part are chosen with certain random but in a way that agreements are possible, satisfying the next condition:

$\forall \mathrm{i} \in$ Attributes, and weight $[\mathrm{i}]>0, \forall \mathrm{j} \in$ Attributes, and weight $[\mathrm{j}]<0$ :

I peso[j] $\cdot$ threshold[j] $\mid>$ peso[i] $\cdot$ threshold[i] .

Finally, the initial offer from the merchant is computed from the next equation:

$$
\forall \mathrm{i} \in \text { Attributes, offer }[\mathrm{i}]=\text { threshold }[\mathrm{i}]+\frac{\text { benefit }}{\text { weigth }[i] \cdot \operatorname{dim}} .
$$

To obtain a crisp counteroffer, we use parameter $\lambda$ in simplex method in lineal programming with several goals [3]. The goals are: maximize benefits and minimize the distance with the offer of merchants. Some restrictions were posed over such goal function:

$$
\begin{aligned}
& \sum_{\mathrm{i}} \text { weight }[\mathrm{i}] \cdot \mathrm{x}_{\mathrm{i}}>=\text { benefit }-\sum_{\mathrm{i}} \text { weight }[\mathrm{i}] \cdot \operatorname{offer}[\mathrm{i}] \text {. } \\
& \forall \mathrm{j} \in \text { Attributes, and weight }[\mathrm{j}]>0 \text { : } \\
& \mathrm{x}_{\mathrm{j}}>=\max (0, \text { threshold }[\mathrm{j}] \text {-offer }[\mathrm{j}]) \text {, } \\
& \mathrm{x}_{\mathrm{j}}<=\text { offer[j] } \cdot \lambda \cdot \text { weight }[\mathrm{j}] /(\text { weight }[\mathrm{j}] \text {-weight }[\mathrm{k}]) \text {. } \\
& \forall \mathrm{k} \in \text { Attributes, and weight }[\mathrm{k}]<0 \text { : } \\
& \mathrm{x}_{\mathrm{k}}>=\max (0, \text { offer[k]-threshold }[\mathrm{k}]) \text {, } \\
& \mathrm{x}_{\mathrm{k}}<=\operatorname{offer}[\mathrm{k}] \cdot \lambda \cdot \mid \text { weight}[\mathrm{k}] / \text { (weight[j]-weight[k]) } \mid \text {. }
\end{aligned}
$$

The first of the alternatives proposed is a piece-wise definition of a trapezium over a dominion of fictitious values. Then, the shape and relative position of the trapezium should reflect in an indirect way the preferences of the buyer over such attribute. So buyers assign his own scale to the dominion of fictitious values using a value called $\mathrm{m}$. The corresponding dominion results then from offer[i]-m to offer[i]+m. The value $m$ is computed from:

$$
\mathrm{m}=\max (\operatorname{loffer}[\mathrm{i}]-\text { threshold}[\mathrm{i}] \mathrm{I}, \mathrm{|} \text { benefit / weight[i] }- \text { offer [i] I ) . }
$$

Therefore the four points that define the fuzzy set are the next ones:

$$
\begin{aligned}
& \forall \mathrm{j} \in \text { Attributes, and weight }[\mathrm{j}]>0 \text { : } \\
& \qquad \mathrm{x}_{\mathrm{j}}{ }^{0}=(\mathrm{m}+\operatorname{threshold}[\mathrm{j}] \text {-offer }[\mathrm{j}]) \cdot 100 / \mathrm{m} \cdot 2 \\
& \mathrm{x}_{\mathrm{j}}{ }^{1}=(\mathrm{m}+\max (\text { threshold }[\mathrm{j}], \text { benefit } /(\text { weight }[\mathrm{j}] \cdot \operatorname{dim})) \text {-offer }[\mathrm{j}]) \cdot 100 / \mathrm{m} \cdot 2 \\
& \qquad \mathrm{x}_{\mathrm{j}}{ }^{2}=99.999, \mathrm{x}_{\mathrm{j}}{ }^{3}=100 \\
& \forall \mathrm{k} \in \text { Attributes, and weight }[\mathrm{k}]<0:
\end{aligned}
$$

$$
\mathrm{x}_{\mathrm{k}}{ }^{0}=0, \mathrm{x}_{\mathrm{k}}{ }^{1}=0.001
$$

$\mathrm{x}_{\mathrm{k}}{ }^{2}=(\mathrm{m}+\min ($ lbenefit $/$ weight $[\mathrm{k}]-$ offer[k]l/dim, offer[k] $)-$ offer[k] $)$

$\cdot 100 / \mathrm{m} \cdot 2$

$\mathrm{x}_{\mathrm{k}}^{3}=(\mathrm{m}+$ threshold$[\mathrm{k}]$-offer $[\mathrm{k}]) \cdot 100 / \mathrm{m} \cdot 2 \mathrm{x}+\mathrm{y}=\mathrm{z}$. 
The second alternative proposed uses two linguistic labels per each attribute. One of them represents one of the fuzzy set, and the other label represents a linguistic modifier where modifiers only changes the gradient of the sides of the trapezium. In order to generate this pair of labels from an offer of the merchant, two values are computed: distance and gradient with the next equations:

$$
\begin{aligned}
& \forall \mathrm{j} \in \text { Attributes, and weight }[\mathrm{j}]>0: \\
& \qquad \begin{array}{l}
\text { distance }=\operatorname{offer}[\mathrm{j}] \cdot \text { weight }[\mathrm{j}] \cdot \operatorname{dim} / \text { benefit }, \\
\text { gradient }=
\end{array}, \frac{\text { offer }[j]-\text { threshold }[j]}{\text { benefit } / \text { (weight }[j] \cdot \operatorname{dim})- \text { threshold }[j]},
\end{aligned}
$$

$\forall \mathrm{k} \in$ Attributes, and weight $[\mathrm{k}]<0$ :

$$
\text { gradient }=\frac{\text { distance }=1+\text { offer }[\mathrm{k}] \text { weight }[\mathrm{k}] \cdot \operatorname{dim} / \text { benefit },}{\text { benefit } /(\text { weight }[k] \cdot \mathrm{dim})+\text { threshold }[k]} .
$$

Distances determine the first linguistic label, while gradients determine the linguistic modifier. When the merchant receives such linguistic labels, a graphical interpretation of the linguistic label is drawn over the dominion scaled with the preferences of the merchant. The crossover of the fuzzy set built up the preferences of the merchant and the fuzzy set corresponding to the interpretation of the linguistic labels, is then rescaled to obtain a crisp offer answering to the previous fuzzy counter-offer based on linguistic labels.

\section{Experimental Results}

We have tested an illustrative example of 100 negotiations about two issues: price and quality. In each of these 100 negotiations, buyers and merchants use different preferences functions computed randomly (essentially weights and thresholds of the negotiation attributes). It is also stated that negotiations fail after a sequence of 10 pairs of offers and counter-offers. With all these conditions we obtained the next results:

Table 1. Agreements, benefit and messages involved in negotiations.

\begin{tabular}{|c|c|c|c|}
\hline & Messages needed & Benefit obtained & \% of agreements \\
\hline Crisp & 2.82 & 80.10 & $44 \%$ \\
\hline Fuzzy Set & 1.79 & 73.09 & $86 \%$ \\
\hline Fuzzy Label & 5.58 & 80.29 & $48 \%$ \\
\hline
\end{tabular}

As we can see in table 1, for the negotiations involving fuzzy sets, a higher percentage of success is reached wasting less computational resources, although the benefit obtained is lower than the other two alternatives. So it seems that fuzzy sets are specially useful to face fast negotiations and to avoid failed negotiations. Furthermore, the 
velocity of convergence of this alternative does not mean an easier acquisition of buyers' shopping profile as it is shown in [4]. On the other hand, negotiations involving fuzzy labels last much more than the others, and obtain a percentage of success similar to negotiations involving crisp counter-offers. Nevertheless the final agreement obtained satisfies better the preferences of buyers. So this type of counter-offer obtains better agreements lasting more time.

\section{Conclusions}

The main contribution relies on the application of fuzzy logic to agent-mediated negotiations. Our proposal first shows how to make negotiation dialog more human, and second, how to make negotiations more profitable for buyers without wasting computational resources in no-way-out negotiations.

\section{References}

1. Rosenchein, J. Zlotkin G.: Rules of Encounter: Designing conventions for automated negotiation among computers, MIT Press 1994

2. Sierra C., Jennings N.R., Noriega P., Parsons S.: A framework for argumentation-based negotiation. Intelligent Agents IV, number 1365 in LNAI, Springer (1997) 177-192

3. Zadeh L.A.,: Fuzzy Sets Information and Control, nº 8, (1965) 338-353.

4. Carbo, J., Ledezma A.,: A machine learning based evaluation of a negotiation involving fuzzy counter-offers. In Procs. Int. Conf. on Atlantic Web Intelligence (2003). 